\title{
Targeting the Cannabinoid Pathway Limits the Development of Fibrosis and Autoimmunity in a Mouse Model of Systemic Sclerosis
}

\author{
Amélie Servettaz, ${ }^{\star \dagger}$ Niloufar Kavian, ${ }^{*}$ Carole Nicco, ${ }^{*}$ \\ Vanessa Deveaux, ${ }^{\ddagger}$ Christiane Chéreau, ${ }^{\star \S}$ \\ Andrew Wang," Andreas Zimmer," \\ Sophie Lotersztajn, ${ }^{\ddagger}$ Bernard Weill, ${ }^{*}$ \\ and Frédéric Batteux ${ }^{\star \S}$

\begin{abstract}
From the Laboratoire d'Immunologie Biologique et EA 1833," Faculté de Médecine, AP-HP Hôpital Cochin, Université Paris Descartes, Paris, France; the Service de Médecine Interne, Maladies Infectieuses, Immunologie Clinique, ${ }^{\dagger}$ Faculté de Médecine de Reims, Hôpital Robert Debré, Reims, France; INSERM, Unité 955, Institut Mondor de Recherche Biomédicale Créteil, Université Paris 12, Faculté de Médecine, UMR-S955, Descartes, Paris, France; the Department of Immunology." University of Texas Southwestern Medical Center, Dallas, Texas; and the Department of Molecular Psychiatry." University of Bonn, Bonn, Germany
\end{abstract} \\ Créteil, France; ERTi, ${ }^{\circledR}$ Faculté de Médecine, Université Paris
}

Our aim was to evaluate the roles of the cannabinoid pathway in the induction and propagation of systemic sclerosis (SSc) in a mouse model of diffuse SSc induced by hypochlorite injections. BALB/c mice injected subcutaneously every day for 6 weeks with PBS or hypochlorite were treated intraperitoneally with either WIN-55,212, an agonist of the cannabinoid receptors 1 (CB1) and receptors 2 (CB2), with JWH-133, a selective agonist of $\mathrm{CB2}$, or with PBS. Skin and lung fibrosis were then assessed by histological and biochemical methods, and the proliferation of fibroblasts purified from diseased skin was assessed by thymidine incorporation. Autoantibodies were detected by ELISA, and spleen cell populations were analyzed by flow cytometry. Experiments were also performed in mice deficient for $\mathrm{CB} 2$ receptors $\left(\mathrm{Cnr}^{-/-}\right)$. Injections of hypochlorite induced cutaneous and lung fibrosis as well as increased the proliferation rate of fibroblasts isolated from fibrotic skin, splenic B cell counts, and levels of anti-DNA topoisomerase- 1 autoantibodies. Treatment with WIN-55,212 or with the selective CB2 agonist JWH-133 prevented the development of skin and lung fibrosis as well as reduced fibroblast proliferation and the development of autoantibodies. Experi- ments performed in $\mathrm{CB} 2$-deficient mice confirmed the influence of $\mathrm{CB} 2$ in the development of systemic fibrosis and autoimmunity. Therefore, we demonstrate that the $\mathrm{CB} 2$ receptor is a potential target for the treatment of SSc because it controls both skin fibroblast proliferation and the autoimmune reaction. (Am J Pathol 2010, 177:187-196; DOI: 10.2353/ajpath.2010.090763)

Systemic sclerosis (SSc) is a connective tissue disorder characterized by vascular alterations, extensive fibrosis, and immunological dysregulations associated with specific autoantibodies (AAbs). ${ }^{1}$ The involvement of visceral organs determines the prognosis of the disease, which can be life threatening. Despite progresses in the treatment of some visceral complications, no treatment has been designed to date that can cure SSc, in part because the mechanisms underlying the disease remain unclear. ${ }^{2,3}$

Endogenous cannabinoids are lipid molecules produced by most cell types in the brain and various peripheral tissues. They exert a broad range of biological effects that are reproduced by $\Delta 9$-tetra-hydroxycannabinol, the main constituent of marijuana. Anandamide and 2-arachidonoylglycerol are the two most widely studied endocannabinoids. They exert their effects through the binding to two protein G-coupled specific receptors: cannabinoid receptors 1 (CB1) and receptors 2 (CB2)., ${ }^{4,5}$ The CB1 receptor, predominantly expressed in brain, is present to a lesser extent in endothelium and liver. The CB2 receptor has been initially detected in hematopoietic and immune cells, but recent studies have identified this receptor in fibroblasts, endothelial cells, liver cells, and myocytes. ${ }^{6-13}$ Moreover, the ex-

\footnotetext{
Supported by a grant from the "Fondation pour la Recherche Médicale (FRM)" (N.K.)

A.S. and N.K. contributed equally to this work.

Accepted for publication March 15, 2010.

Supplemental material for this article can be found on http://ajp. amjpathol.org.

Address reprint requests to Dr. Frédéric Batteux, Université Paris Descartes, Faculté de Médecine, Laboratoire d'immunologie, EA 1833, IFR Alfred Jost, 75679 Paris cedex 14, France. E-mail: frederic.batteux@cch. ap-hop-paris.fr.
} 
pression of the CB2 receptor can be influenced by various pathological conditions such as inflammation.

In addition to their well-characterized psychoactive effects, cannabinoids modulate various key functions, especially cardiovascular and endothelial functions. The endocannabinoid pathway abrogates the activation of endothelial cells isolated from sinusoidal vessels of human liver and from human coronary arteries and prevents ischemia/reperfusion damages in the liver, ${ }^{13-15}$ the heart, and the brain. ${ }^{16,17}$ This role is assumed by CB2 agonists that act as modulators of endothelial cell activation and endothelial/ inflammatory cell interaction and down-regulate adhesion molecules such as intracellular cell adhesion molecule 1 and vascular cell adhesion molecule $1 .{ }^{18}$ Moreover, natural or synthetic cannabinoids display immunomodulatory effects on the proliferation and apoptosis of T and B lymphocytes, the activation of macrophage, and the production of cytokines and chemokines. ${ }^{19-21}$ Most of these effects are CB2 receptor-dependent. In addition, recent data have shown that CB2 receptor agonists counteract liver fibrogenesis. ${ }^{12,22}$ CB2 receptors are also present in the skin, ${ }^{23}$ and their activation prevents bleomycin-induced dermal fibrosis in the mouse. ${ }^{24}$

Because endothelial cells, fibroblasts, and immune cells are dysregulated in SSc and are also the targets of cannabinoids, we were prompted to investigate the role of these molecules in SSc. To this end, we used a recently described murine model of SSc that recapitulates the main features of the cutaneous diffuse form of the human disease. ${ }^{25}$

\section{Materials and Methods}

\section{Animals, Cells, and Chemicals}

Specific pathogen-free 6-week-old female BALB/c and C57BL/6 CB2 ${ }^{+/+}$mice were purchased from Harlan (Gannat, France) and maintained with food and water ad libitum. To obtain single mutant mice with a targeted mutation of the Cnr2 gene on an inbred congenic genetic background, heterozygous $\mathrm{Cnr}^{+/-}$mice were backcrossed with wild-type C57BI/6J animals (The Jackson Laboratory, Bar Harbor, ME) over 10 generations. Heterozygous mice from the N10 generation were intercrossed to homozygous $\mathrm{Cnr}^{-/-}$animals (CB2 ${ }^{-/-}$mice). ${ }^{26}$ All mice were housed in autoclaved cages with free access to food and water. They were given humane care according to the guidelines of our institution. All cells were cultured as previously reported. ${ }^{27,28}$ All chemicals, except for monoclonal antibodies, were from Sigma (Saint-Quentin Fallavier, France) except JWH-133 (Tocris Bioscience, Ellisville, MO).

\section{Induction of SSc by Subcutaneous Injections of a HOCl-Generating Solution to BALB/C Mice}

Six week-old BALB/c mice were randomly distributed into experimental and control groups $(n=21$ per group). One hundred microliters of a solution generating $\mathrm{HOCl}$ were injected subcutaneously into the shaved back of the mice, using a 27-gauge needle, every day for 6 weeks, as previously described ( $\mathrm{HOCl}$ mice). ${ }^{25}$ Control groups received injections of $100 \mu$ sterilized PBS (PBS mice). All agents were prepared extemporaneously. $\mathrm{HOCl}$ was produced by adding $166 \mu \mathrm{l} \mathrm{NaClO}$ solution (2.6\% as active chlorine) to $11.1 \mathrm{ml} \mathrm{KH_{2 }} \mathrm{PO}_{4}$ solution (100 $\mathrm{mmol} / \mathrm{L}, \mathrm{pH} 7.2){ }^{29} \mathrm{HOCl}$ concentration was determined by spectrophotometry at $292 \mathrm{~nm}$ (molar absorption coefficient $=350 \mathrm{M}^{-1} \mathrm{~cm}^{-1}$ ).

\section{Treatment by Cannabinoid Agonists}

$\mathrm{HOCl}$ and PBS BALB/c mice were randomized and treated simultaneously by intraperitoneal injections either with WIN-55,212, a nonselective CB1 and CB2 agonist, or JWH-133, a selective CB2 agonist, or vehicle alone for 6 weeks ( $n=14$ per group). Cannabinoid agonists were given 5 days a week from Monday to Friday. The doses increased each week: WIN-55,212 was started at 0.5 $\mathrm{mg} / \mathrm{kg}$ per day the first week, and then 1, 2, 3, 4, and 5 $\mathrm{mg} / \mathrm{kg}$ per day the following weeks; $\mathrm{JWH}-133$ was started at $1 \mathrm{mg} / \mathrm{kg}$ per day, and then $1.5,2,2.5,3$, and $4 \mathrm{mg} / \mathrm{kg}$ per day. WIN-55,212 and JWH-133 were reconstituted with DMSO, aliquoted, and stored as stock solutions at a concentration of $1 \mathrm{mg} / \mathrm{ml}$ at $-20^{\circ} \mathrm{C}$. Each day, the stock solutions were diluted in PBS. One week after the end of the subcutaneous and peritoneal injections, the animals were killed by cervical dislocation. Serum samples were collected and stored at $-80^{\circ} \mathrm{C}$ until use. Lungs were removed from each mouse. One lung was stored at $-80^{\circ} \mathrm{C}$ for collagen assay. The remaining lung was reinflated by injection of $10 \%$ phosphate buffered formalin fixative for 24 hours and then washed and stored in $70 \%$ ethanol fixative. A skin biopsy was performed on the back region with a punch ( $6 \mathrm{~mm}$ of diameter), involving the skin and the underlying muscle of the injected area. Samples were stored at $-80^{\circ} \mathrm{C}$ for determination of collagen content or fixed in $10 \%$ neutral buffered formalin for histopathological analysis. All tissues were examined by a pathologist blind with respect to the experimental groups.

\section{Induction of SSc by Subcutaneous Injections of a HOCl-Generating Solution to C57BL/6 $\mathrm{CB2}^{-1-}$ Mice}

Ten-week-old C57BL/6 $\mathrm{CB} 2^{-/-}$and $\mathrm{CB} 2^{+/+}$mice were randomly distributed into experimental and control groups ( $n=5$ per group). The experimental procedure was similar to that applied to BALB/C mice, except that $\mathrm{C} 57 \mathrm{BL} / 6 \mathrm{CB}^{+/+}$and $\mathrm{CB} 2^{-/-}$mice were killed after three weeks of subcutaneous injections.

\section{Assessment of Dermal Thickness}

Skin thickness of the shaved back of mice was measured one day before sacrifice with a caliper and expressed in millimeters.

\section{Histopathological Analysis}

Fixed lung and skin pieces were embedded in paraffin. A 5 - $\mu \mathrm{m}$-thick tissue section was prepared from the midpor- 
tion of paraffin-embedded tissue and stained either with hematoxylin eosin and safran or with picro-sirius red. Slides were examined by standard brightfield microscopy (Olympus BX60, Tokyo, Japan) by a pathologist who was blinded to the assignment of the animal group.

\section{Collagen Content in Skin and Lung}

Skin taken from the site of injection and lung pieces were diced using a sharp scalpel, put into aseptic tubes, thawed, and mixed with pepsin (1:10 weight ratio) and $0.5 \mathrm{M}$ acetic acid overnight at room temperature under stirring. Collagen content assay was based on the quantitative dye-binding Sircol method (Biocolor, Belfast, N. Ireland). ${ }^{30}$

\section{Isolation of Fibroblasts from the Skin of Mice and Proliferation Assays}

Skin fragments from the back of mice were collected at the time of sacrifice. Skin samples were digested with "Liver Digest Medium" (Invitrogen) for 1 hour at $37^{\circ} \mathrm{C}$. After three washes in complete medium, cells were seeded into sterile flasks and isolated fibroblasts were cultured in DMEM/Glutamax-I supplemented with 10\% heat-inactivated fetal calf serum and antibiotics at $37^{\circ} \mathrm{C}$ in humidified atmosphere with 5\% CO2. For proliferation assays, primary fibroblasts $\left(2 \times 10^{3}\right.$ per well $)$ were seeded in 96-well plates and incubated with $150 \mu \mathrm{l}$ of culture medium with $10 \%$ fetal calf serum at $37^{\circ} \mathrm{C}$ in $5 \%$ $\mathrm{CO}_{2}$ for 48 hours. Cell proliferation was determined by pulsing the cells with $\left[{ }^{3} \mathrm{H}\right]$ thymidine $(1 \mu \mathrm{Ci}$ per well) during the last 16 hours of culture. Results were expressed as absolute numbers of counts per minute.

\section{Effect of Various Concentrations of WIN-55,212 and JWH-133 on the in Vitro Proliferation of Skin Fibroblasts}

Fibroblasts isolated from the skin of $\mathrm{HOCl} \mathrm{BALB} / \mathrm{c}$ mice were seeded in 96-well plates $\left(4 \times 10^{3}\right.$ per well $)$ and incubated with 10,20 , or $40 \mu \mathrm{mol} / \mathrm{L}$ WIN-55,212 or JWH133 in culture medium supplemented with $10 \%$ fetal calf serum at $37^{\circ} \mathrm{C}$ in $5 \% \mathrm{CO}_{2}$ for 48 hours. Cell proliferation was determined as previously described.

\section{Flow Cytometric Analysis of Spleen Cell Subsets}

Cell suspensions from spleens were prepared after hypotonic lysis of erythrocytes. Cells were incubated with the appropriately labeled antibody $(\mathrm{Ab})$ at $4^{\circ} \mathrm{C}$ for 45 minutes in PBS with $0.1 \%$ sodium azide and $5 \%$ normal rat serum to block nonspecific binding. Cell suspensions were then subjected to four-color analysis on a FACS Canto flow cytometer (BD Biosciences, San Jose, CA). The monoclonal Abs used in this study were as follows: anti-B220-PE mAb, anti-CD11b-FITC mAb, anti-CD4APC-Cy7 mAb, and anti-CD8-PE-Cy7 mAb (BD Pharmingen, Franklin, $\mathrm{NJ}$ ).

\section{Assays of Serum Immunoglobulins and AAbs}

Serum samples were frozen at the time of sacrifice, and all samples were analyzed at the same time. Levels of antiDNA topoisomerase $1 \mathrm{lg}$ G Abs were detected by ELISA on microtiter plates (Immunovision, Springdale, AR) coated with $\mathrm{Scl} 70$ antigen. Levels of total mouse lgG and IgM Abs, of anti-dsDNA IgG Abs, of anti-cardiolipin IgG Abs, and of IgM rheumatoid factors were measured using standard ELISA as previously described. ${ }^{31}$ A 1:50 serum dilution was used for the determination of all AAbs.

\section{Statistical Analysis}

All quantitative data are expressed as means \pm SEM. Data were compared using the Mann-Whitney nonparametric test or the Student paired $t$ test. When analysis included more than two groups, one way analysis of variance was used. A $P$ value $<0.05$ was considered significant.

\section{Results}

\section{Activation of the Cannabinoid Receptors Prevents the Development of Skin Fibrosis in $\mathrm{HOCl}$ mice}

As previously observed, subcutaneous injections of $\mathrm{HOCl}$ in BALB/c mice induced an increase in dermal thickness and in the concentration of acid- and pepsin-soluble type I collagen in the skin versus injections of PBS $(P<0.0001$ in both cases; Figure 1, A and B). Histopathological analysis confirmed the dermal fibrosis (Figure 1A).

To evaluate whether the activation of cannaboid receptors affects the development of dermal fibrosis in this model of SSc, mice exposed to $\mathrm{HOCl}$ were simultaneously treated with WIN-55,212, an agonist of both CB1 and CB2 receptors. WIN-55,212 reduced the dermal thickness and the accumulation of collagen induced by $\mathrm{HOCl}(P=0.0007$ for dermal thickness and $P=0.0006$ for collagen concentration in the skin, versus untreated mice exposed to $\mathrm{HOCl}$; Figure 1, A and B). Those results were confirmed by histopathological analysis of skin biopsies stained with hematoxylin and eosin (Figure 1C) and with picro-sirius red staining (Figure $2 \mathrm{~A}$ ), which showed a decrease in dermal thickness in $\mathrm{HOCl}-\mathrm{BALB} / \mathrm{C}$ mice treated with WIN-55,212.

We next investigated the effect JWH-133, a selective agonist of $\mathrm{CB} 2$, on the development of dermal fibrosis induced by $\mathrm{HOCl}$. JWH-133 significantly reduced the dermal thickness and the accumulation of collagen in the skin of $\mathrm{HOCl}$ mice $(P=0.0004$ for dermal thickness and $P=0.005$ for collagen concentration in the skin, versus untreated $\mathrm{HOCl}$ mice; Figure $1, \mathrm{~A}$ and $\mathrm{B}$ ). These results, confirmed by histopathological analysis (Figures $1 \mathrm{C}$ and $2 \mathrm{~A}$ ), show that the selective activation of $\mathrm{CB} 2$ is sufficient to reduce the fibrotic process triggered by $\mathrm{HOCl}$. 
A

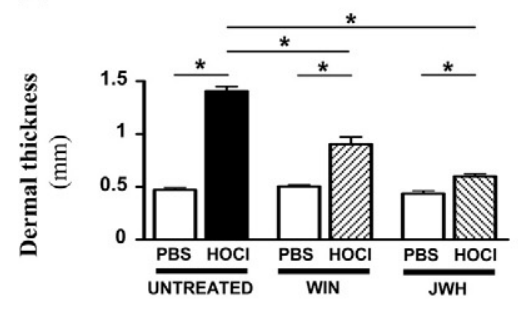

B

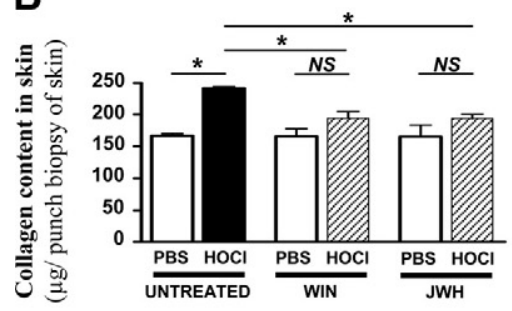

C

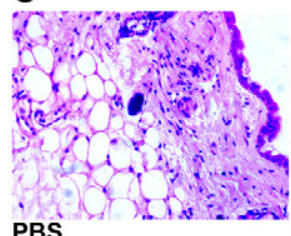

PBS

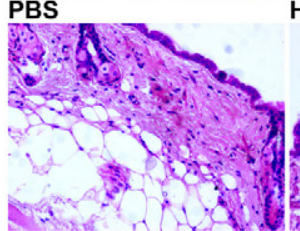

PBS+JWH-133

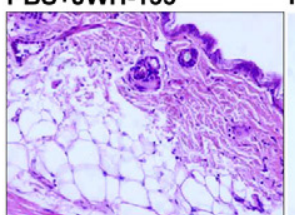

PBS+WIN-55212

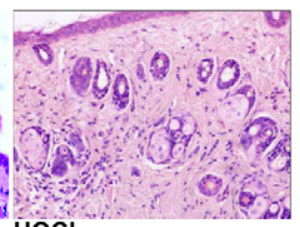

$\mathrm{HOCl}$
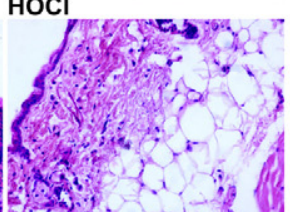

$\mathrm{HOCl}+\mathrm{JWH}-133$

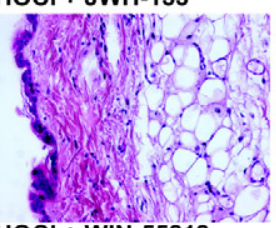

HOCl + WIN-55212
D

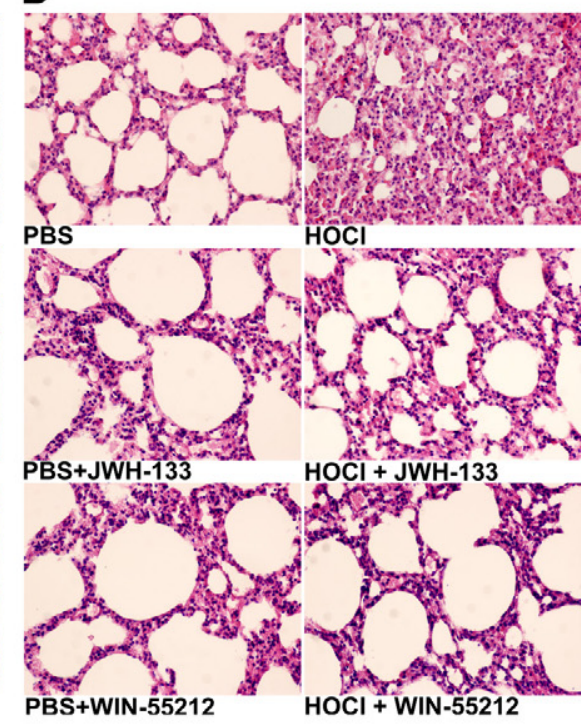

Figure 1. Effects of cannabinoid agonists on HOCl-induced fibrosis of the skin and of the lung in BALB/C mice. BALB/c mice were injected daily for six weeks with either an $\mathrm{HOCl}$-generating agent or PBS $(n=7$ per group) and simultaneously treated or not with either WIN-55212, a nonselective CB1 and CB2 agonist, JWH-133, a selective CB2 agonist, or vehicle control. Skin and lungs from those mice were collected at the time of sacrifice. A: Dermal thickness, as measured on skin in the injected areas of BALB/c mice. B: Collagen content in 6-mm punch biopsy of skin as measured by the quantitative dye-binding Sircol method. Representative lung sections from BALB/c mice. C: Representative skin sections taken in the injected areas from BALB/c mice. WIN-55212 and JWH-133 treatment abrogated the development of HOCl-induced skin fibrosis in mice. Tissue sections were stained with hematoxylin and eosin (Olympus DP70 Controller, X 20). D: Tissue sections were stained with hematoxylin and eosin (Olympus DP70 Controller, $\times 10$ ). E: Collagen content in lung as measured by the quantitative dye-binding Sircol method. WIN-55212 and JWH-133 treatment abrogated the development of HOCl-induced lung fibrosis in mice. In $\mathbf{A}, \mathbf{C}$, and $\mathbf{E}$, values are means \pm SEM of data. Mean values were compared using unpaired Mann-Whitney $U$ tests. ${ }^{*} P<0.05$; NS indicates nonsignificant.

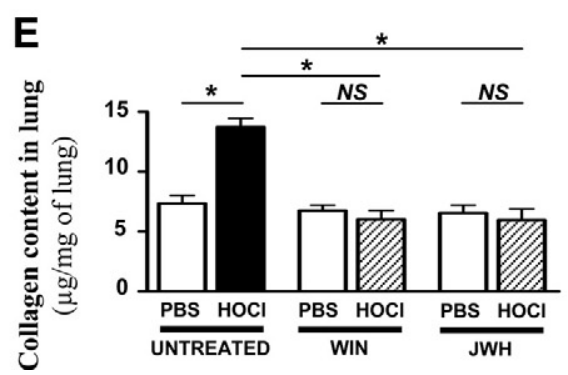

\section{Activation of the Cannabinoid Receptors Prevents the Development of Lung Fibrosis in HOCl Mice}

In addition to skin fibrosis, HOCl-treated BALB/c mice developed lung fibrosis, as shown by histopathological analysis (Figure 1D) and by the higher concentration of type I collagen in the lungs of $\mathrm{HOCl}$ mice as compared with mice treated with PBS ( $P=0.0002$; Figure 1E). WIN-55,212 abrogated the development of lung fibrosis induced by $\mathrm{HOCl}$, as shown by histopathological analysis and by the weaker accumulation of type I collagen in lungs $(P=0.0002$ for WIN-treated versus untreated $\mathrm{HOCl}$ mice; Figures 1, $\mathrm{D}$ and $\mathrm{E}$, and $2 \mathrm{~B}$ ).

The selective agonist of CB2, JWH-133, also reduced the concentration of type I collagen in the lungs compared with untreated $\mathrm{HOCl}$ mice ( $P=0.002$ for $\mathrm{JWH}$-treated versus untreated $\mathrm{HOCl}$ mice; Figure $1 \mathrm{E}$ ). Those data were confirmed by the histopathological analysis of lung biopsies stained with hematoxylin and eosin (Figure 1D) and with picro-sirius red staining (Figure 2B), which showed a decreased fibrosis in BALB/c mice submitted to $\mathrm{HOCl}$ injections and simultaneously treated with $\mathrm{JWH}-133$.

Immunohistochemistry analysis of lung tissue sections from BALB/c mice injected with $\mathrm{HOCl}$ evidenced an inflammatory infiltrate mostly consisting of $\mathrm{T}$ lymphocytes. WIN-55,212 and JWH-133 reduced the pulmonary T cell infiltrate triggered by $\mathrm{HOCl}$ (see supplemental Figure $\mathrm{S} 1$ at $h$ ttp://ajp.amjpathol.org).

\section{Activation of Cannabinoid Receptors Normalized the Rate of Dermal Fibroblast Proliferation in Vivo and in Vitro}

We next investigated whether the activation of the cannabinoid signaling pathway modified the growth of fibroblasts isolated from fibrotic skin. Skin fibroblasts isolated from $\mathrm{HOCl}$ mice displayed a higher proliferation rate than fibroblasts obtained from mice injected with PBS $(P=$ 0.0004; Figure $3 \mathrm{~A}$ ). By contrast, the rate of proliferation of fibroblasts isolated from $\mathrm{HOCl}$ mice treated with WIN55,212 was lower than that of fibroblasts isolated from mice injected with PBS $(P=0.02$ for $\mathrm{HOCl}$ mice treated with WIN-55,212 versus $\mathrm{HOCl}$ mice not treated with WIN55,212; $P=0.71$ for $\mathrm{HOCl}$ mice treated with WIN-55,212 versus PBS mice treated with WIN-55,212; Figure 3A).

The rate of proliferation of skin fibroblasts was also reduced when $\mathrm{HOCl}$ mice were treated with the selective CB2 agonist JWH-133, compared with that of fibroblasts isolated from $\mathrm{HOCl}$ mice without any treatment $(P=0.02$ for $\mathrm{HOCl}$ mice treated with $\mathrm{JWH}-133$ versus $\mathrm{HOCl}$ mice and untreated with $\mathrm{JWH}-133$ and $P=0.13$ for $\mathrm{HOCl}$ mice treated with $\mathrm{JWH}-133$ versus PBS mice treated with $\mathrm{JWH}$ 133; Figure 3A).

Because fibroblasts from $\mathrm{HOCl}$ mice displayed an abnormal phenotype with an excessive rate of proliferation, additional experiments were performed to assess 
A

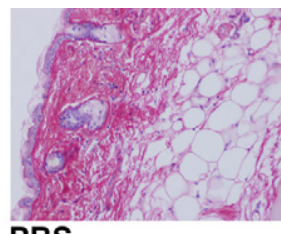

PBS

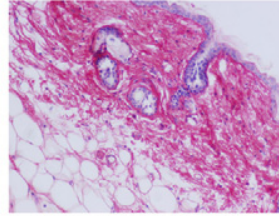

$\mathrm{HOCl}+\mathrm{JWH}-133$

B

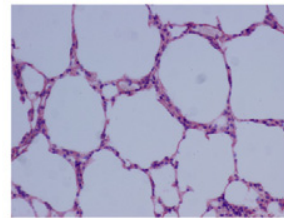

PBS

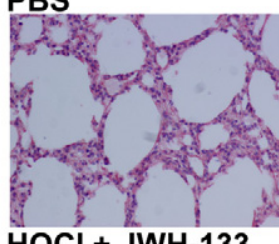

$\mathrm{HOCl}+\mathrm{JWH}-133$

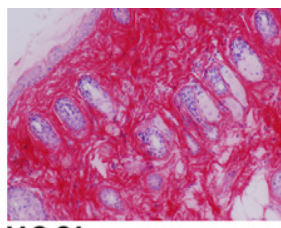

$\mathrm{HOCl}$

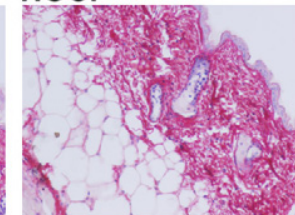

$\mathrm{HOCl}+\mathrm{WIN}-55212$

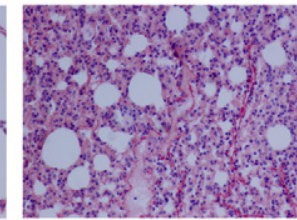

$\mathrm{HOCl}$

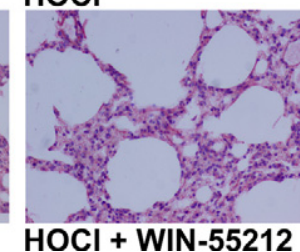

Figure 2. Effects of cannabinoid agonists on HOCl-induced fibrosis of the skin and of the lung in $\mathrm{BALB} / \mathrm{c}$ mice: representative sections of skin and lung stained with picro-sirius red. $\mathrm{BALB} / \mathrm{c}$ mice were injected daily for six weeks with either an HOCl-generating agent or PBS ( $n=7$ per group) and simultaneously treated or not with either WIN-55212, a nonselective CB1 and CB2 agonist, or JWH-133, a selective CB2 agonist, or vehicle control. Skin and lungs from those mice were collected at the time of sacrifice. A: Representative skin sections from BALB/C mice WIN-55212 and JWH-133 treatment abrogated the development of HOClinduced skin fibrosis in mice. Tissue sections were stained with picro-sirius red (Olympus DP70 Controller, $\times 20$ ). B: Representative lung sections from BALB/C mice. Tissue sections were stained with picro-sirius red (Olympus DP70 Controller, $\times 10$ ).

whether WIN-55,212 and JWH-133 could directly decrease the rate of fibroblast proliferation in vitro. Skin fibroblasts from $\mathrm{HOCl}$ mice were incubated with 10, 20, or $40 \mu \mathrm{mol} / \mathrm{L}$ WIN-55,212, or JWH-133 or PBS. WIN55,212 reduced the proliferation rate of fibroblasts in vitro in a dose-dependent manner $(P=0.022$ for each concentration of WIN-55,212 tested versus PBS; Figure 3B). For JWH-133, the doses of 10 and $20 \mu \mathrm{mol} / \mathrm{L}$ did not reverse the proproliferative of $\mathrm{HOCl}$ treatment, but at a dose of $40 \mu \mathrm{mol} / \mathrm{L} \mathrm{JWH}-133$ significantly abrogated the rate of proliferation of fibroblasts from $\mathrm{HOCl}$ mice $(P=$ $0.914, P=0.171$, and $P=0.032$ for the respective concentrations of 10,20 , and $40 \mu \mathrm{mol} / \mathrm{L}$ of $\mathrm{JWH}-133$ versus PBS; Figure 3B). Thus, cannabinoid agonists counteracted the proproliferative effect of $\mathrm{HOCl}$ on fibroblasts both in vivo and in vitro and prevented skin and lung fibrosis.

\section{Activation of CB2 Receptors Decreases the Expansion of Splenic B-Cells in HOCl Mice}

We next investigated the effects of the activation of cannabinoid receptors on the immune system because both
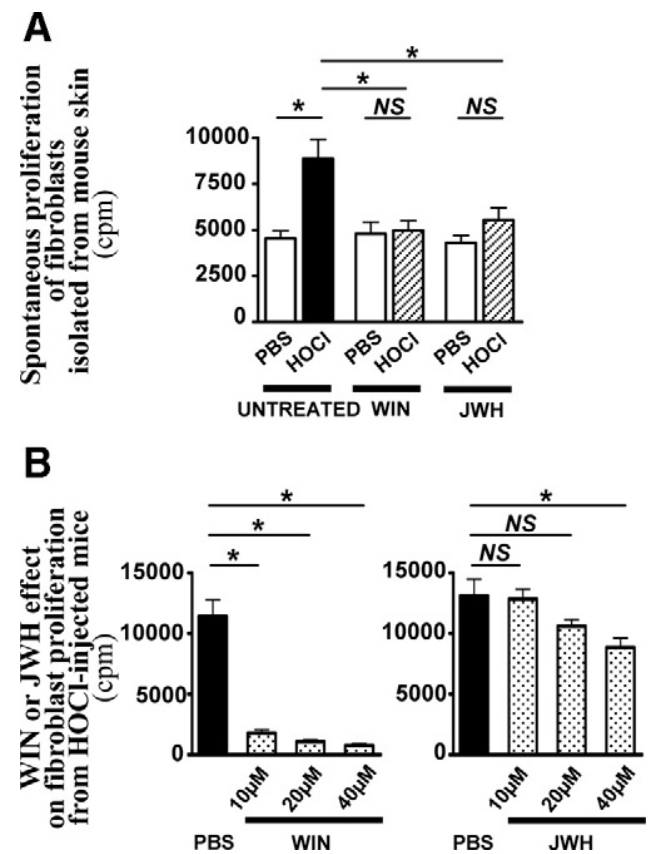

Figure 3. Effect of cannabinoid agonists on fibroblast proliferation $\mathrm{BALB} / \mathrm{c}$ mice were injected daily for 6 weeks with either an $\mathrm{HOCl}$ generating agent or PBS ( $n=7$ per group) and simultaneously treated or not with WIN-55212 or JWH-133 or with vehicle control. Skin biopsies from the injected areas were collected at the time of sacrifice. Fibroblasts were isolated by collagenase digestion of the skin then cultured in complete medium. Cell proliferation was determined by pulsing the cells with [3H]thymidine $(1 \mu \mathrm{Ci} /$ well $)$ during the last 16 hours of culture. A: Spontaneous rate of proliferation of fibroblasts isolated from fibrotic skin of mice submitted to $\mathrm{HOCl}$ or PBS injections and simultaneously treated in vivo with WIN-55212, JW-133, or vehicle alone. B: Direct in vitro effect of WIN-55212 (10, 20, or $40 \mu \mathrm{mol} / \mathrm{L})$ and JWH-133 (10, 20, or $40 \mu \mathrm{mol} / \mathrm{L}$ ) on the growth of fibroblasts isolated from the skin of mice submitted to $\mathrm{HOCl}$ injections for six weeks. Results are expressed as absolute counts per minute $(\mathrm{cpm})$. Values are means \pm SEM of data. Mean values were compared using unpaired Mann-Whitney $U$ tests. ${ }^{*} P<0.05$; NS indicates nonsignificant.

in humans and mice, diffuse SSc is characterized by B cell activation and the production of AAbs. As previously reported, exposure to $\mathrm{HOCl}$ for six weeks increased the total numbers of splenic B220 ${ }^{+} \mathrm{B}$ cells compared with PBS-injected mice ( $P=0.011$; Figure $4 \mathrm{~A})$. No significant difference was observed in the numbers of $C D 11 b^{+}$, $\mathrm{CD}^{+}$, or $\mathrm{CD}^{+}$spleen cells between $\mathrm{HOCl}$ and PBSinjected mice (data not shown).

Activation of the cannabinoid pathway by WIN-55,212 or by the selective $\mathrm{CB} 2$ agonist JWH-133 prevented the increase in splenic $\mathrm{B}$ cell numbers in $\mathrm{HOCl}$ mice $(P=$ 0.003 for $\mathrm{HOCl}$ mice treated by WIN-55,212 versus $\mathrm{HOCl}$ mice; $P=0.003$ for $\mathrm{HOCl}$ mice treated by $\mathrm{JWH}-133$ versus $\mathrm{HOCl}$ mice; Figure $4 \mathrm{~A}$ ).

\section{Activation of CB2 Receptors Decreases the Serum Levels of Anti-DNA-Topoisomerase 1 AAbs Induced by $\mathrm{HOCl}$}

We next tested the effects of WIN-55,212 and JWH-133 on the specific autoimmune response to DNA-topoisomerase 1 that characterizes the cutaneous diffuse SSc phenotype. As previously observed, mice exposed to 
A
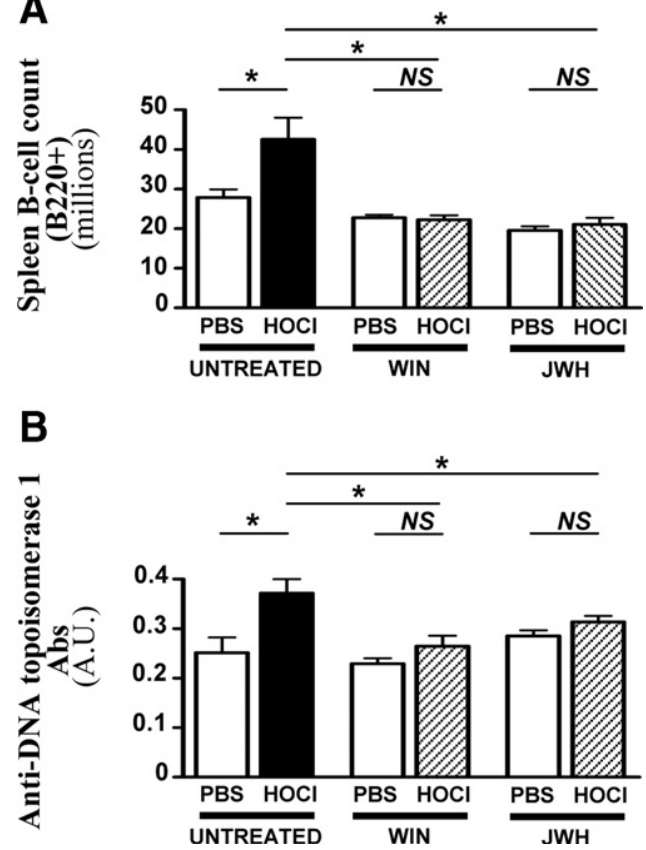

Figure 4. Activation of the cannabinoid pathway abrogated splenic $\mathrm{B}_{22}{ }^{+}$cell expansion and anti-DNA-topoisomerase $\mathrm{Ab}$ production in $\mathrm{HOCl}$ mice. $\mathrm{BALB} / \mathrm{c}$ mice were injected daily for six weeks with either an HOCl-generating agent or PBS ( $n=7$ per group) and simultaneously treated with WIN-55212, JWH-133, or vehicle control. Spleen and serum from those mice were collected at the time of sacrifice. A: Absolute numbers of splenic B220 positive B cells as assessed by flow cytometry. B: Levels of serum anti-DNA-topoisomerase 1 AAbs as detected by ELISA Values are means \pm SEM of data gained from all mice. Mean values were compared using unpaired Mann-Whitney $U$ tests. ${ }^{*} P<0.05$; NS indicates nonsignificant

$\mathrm{HOCl}$ developed anti-DNA topoisomerase $1 \mathrm{lgG}$ Abs $(P=0.002$ versus PBS; Figure 4B). No significant levels of anti-DNA IgG Abs, anticardiolipine IgG Abs or rheumatoid factors were detected in the sera of these mice (data not shown).

Mice treated with WIN-55,212 or JWH-133 did not develop anti-DNA topoisomerase1 IgG Abs after exposure to $\mathrm{HOCl}$ compared with untreated mice $(P=0.002$ for $\mathrm{HOCl}$ mice treated by $\mathrm{WIN}-55,212$ versus $\mathrm{HOCl}$ mice; $P=0.03$ for $\mathrm{HOCl}$ mice treated by $\mathrm{JWH}-133$ versus $\mathrm{HOCl}$ mice; Figure 4B).

Thus, the nonselective cannabinoid agonist WIN-55,212 and the selective CB2 agonist JWH-133 counteracted the proproliferative effects of $\mathrm{HOCl}$ on $\mathrm{B}$ cells and prevented the selective autoimmune response to DNAtopoisomerase 1.

\section{CB2 ${ }^{-/-}$Mice Develop an Enhanced Cutaneous Fibrosis Compared with $\mathrm{CB} 2^{+/+}$Mice}

To further evaluate the role of CB2 receptors in the development of SSc, we performed subcutaneous injections of a $\mathrm{HOCl}$-generating solution or PBS in $\mathrm{CB}^{-1-}$ mice and compared the extension of the induced fibrosis to that observed in $\mathrm{CB}^{+/+}$mice submitted to the same regimen. Because of the rapid establishment of the disease in $\mathrm{CB} 2^{-1-}$ mice, all animals were killed after 3 weeks of treatment to maximize the differences. Subcutaneous injections of $\mathrm{HOCl}$ every day for three weeks induced a significant dermal thickness compared with PBS-injected mice both in $\mathrm{CB}^{-1-}$ and $\mathrm{CB} 2^{+/+}$mice $\left(P<0.0001\right.$ for $\mathrm{CB} 2^{-/-}$mice and $P=0.0002$ for $\mathrm{CB}^{+/+}$mice; Figure $\left.5 \mathrm{~A}\right)$. The dermis was thicker in $\mathrm{CB}^{-/-}$mice than in $\mathrm{CB} 2^{+/+}$mice $(P=0.029$; Figure $5 \mathrm{~A})$. Those results were confirmed by histopathological analysis of skin biopsies, which showed more skin fibrosis in $\mathrm{CB}^{-1-}$ mice than in $\mathrm{CB}^{+/+}$mice submitted to $\mathrm{HOCl}$ injections (Figure 5B). The concentration of acid- and pepsin-soluble type I collagen in the skin extracts of both $\mathrm{CB} 2^{-1-}$ mice and $\mathrm{CB}^{+/+}$mice was higher than in their respective controls injected with PBS $\left(P=0.029\right.$ for $\mathrm{CB}^{-1-}$ mice and $P=$ 0.016 for $\mathrm{CB}^{+/+}$mice versus their respective controls; Figure $5 \mathrm{C})$. The accumulation of collagen in the skin was higher in $\mathrm{CB}^{-/-}$mice than in $\mathrm{CB}^{+/+}$mice $(P=0.029$; Figure 5C).

\section{$\mathrm{CB} 2^{-1-}$ Mice Develop an Earlier and Enhanced Lung Fibrosis Compared With CB2 ${ }^{+/+}$Mice}

In addition to skin fibrosis, $\mathrm{CB} 2^{-1-}$ mice exposed to $\mathrm{HOCl}$ subcutaneously for three weeks developed a lung fibrosis, as shown by the higher concentration of type I collagen in the lungs compared with PBS-injected $\mathrm{CB}^{-1-}$ mice $(P=$ 0.016; Figure 5D) and by histopathological analysis (Figure $5 \mathrm{E}) . \mathrm{CB}^{+/+}$mice displayed a slight lung fibrosis as shown by few foci of fibrosis on histological analysis (Figure $5 \mathrm{E}$ ) and by a $32 \%$ increase in type I collagen content of the lung. However, after three weeks of treatment, this increase did not yet reach significance $(P=0.413$ versus PBSinjected $\mathrm{CB}^{+/+}$mice; Figure 5, D and E).

\section{The Rate of Skin Fibroblast Proliferation Is Higher in $\mathrm{HOCl}-\mathrm{CB}^{-1-}$ Mice Than in $\mathrm{HOCl}-\mathrm{CB} 2^{+/+}$Mice}

We next investigated whether CB2 modulated the growth of fibroblasts isolated from fibrotic skin areas of mice. Skin fibroblasts isolated from $\mathrm{HOCl}-\mathrm{CB}^{-1-}$ mice displayed a higher proliferation rate than fibroblasts obtained from $\mathrm{CB}^{-1-}$ mice injected with PBS ( $P=0.032$; Figure $5 F$ ). Moreover, the rate of proliferation of fibroblasts isolated from $\mathrm{HOCl}-\mathrm{CB} 2^{-1-}$ mice was higher than that of fibroblasts from $\mathrm{HOCl}-\mathrm{CB} 2^{+/+}$mice $(P=0.032$; Figure $5 \mathrm{~F})$.

\section{HOCl Injections Induced a Rapid and High Increase in Splenic B Cells in CB2 ${ }^{-1-}$ Mice}

The consequences of CB2 gene silencing on the activation of the immune system in this model of SSc were then evaluated. Subcutaneous injections of $\mathrm{HOCl}$ induced a significant increase in the total numbers of splenic B220 ${ }^{+}$ $\mathrm{B}$ cells in $\mathrm{CB}^{-1-}$ mice compared with PBS-injected $\mathrm{CB}^{-1-}$ mice $(P=0.016$; Figure $6 \mathrm{~A})$, but no significant difference was observed in the numbers of splenic $B$ cells in $\mathrm{HOCl}-\mathrm{CB} 2^{+/+}$mice compared with PBS-injected $\mathrm{CB}^{+/+}$controls $(P=0.86$; Figure $6 \mathrm{~A}$ ) after only three weeks of $\mathrm{HOCl}$ injections. 
A

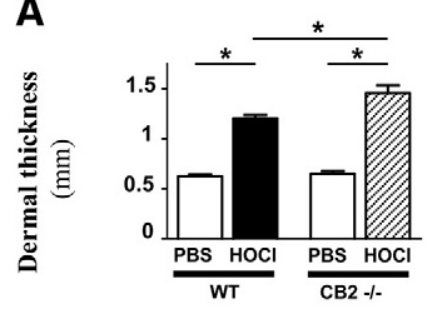

C

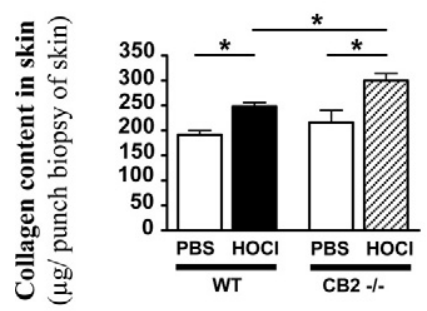

D

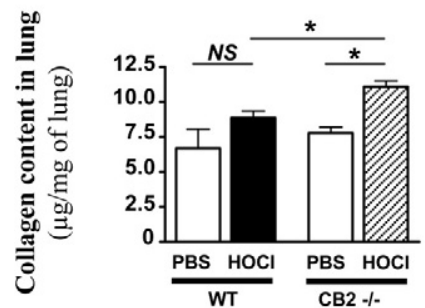

$\mathbf{F}$

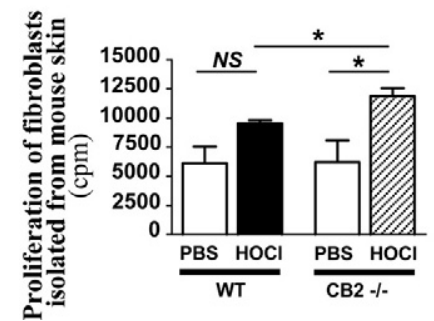

B
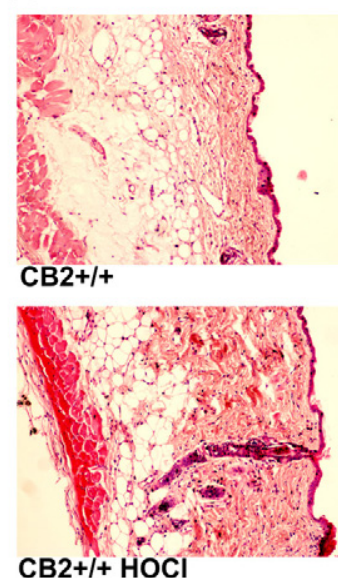

$\mathrm{CB} 2++\mathrm{HOCl}$
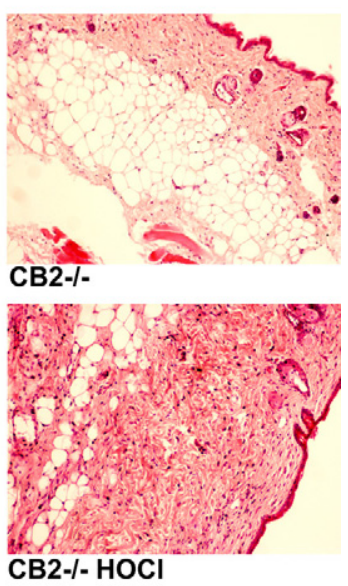

E
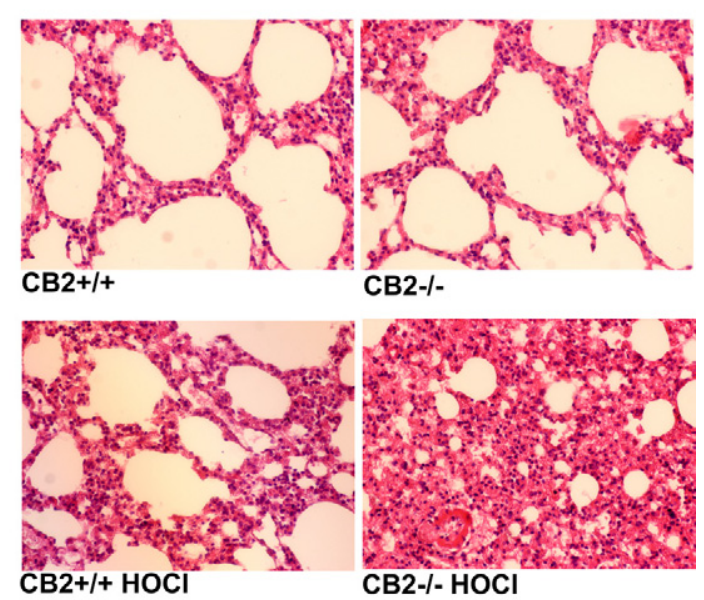

Figure 5. Effect of $\mathrm{CB} 2$ silencing on $\mathrm{HOCl}$ induced skin and lung fibrosis. $\mathrm{CB}^{+/+}$and $\mathrm{CB} 2^{-1-} \mathrm{C} 57 \mathrm{BL} / 6$ mice were injected daily for 3 weeks with either an HOCl-generating agent or PBS ( $n=7$ per group). Skin and lungs from those mice were collected at the time of sacrifice. A: Dermal thickness, as measured on skin in the injected areas of $\mathrm{CB}^{+/+}$and $\mathrm{CB} 2^{-x}$ C57BL/6 mice treated or not with HOCl. B: Representative skin sections taken in the injected areas from $\mathrm{CB} 2^{+/+}$and $\mathrm{CB} 2^{-/-} \mathrm{C} 57 \mathrm{BL} / 6$ mice treated or not with $\mathrm{HOCl}$. Tissue sections were stained with hematoxylin and eosin (Olympus DP70 Controller, $\times 10$ ). Skin fibrosis was increased in $\mathrm{CB} 2^{-/-}$mice. C: Collagen content in 6-mm punch biopsies of skin as measured by the quantitative dye-binding Sircol method. D: Collagen content in lung as measured by the quantitative dye-binding Sircol method. E: Representative lung sections from $\mathrm{CB}^{+/+}$and $\mathrm{CB}^{-1}$ C57BL/6 mice treated or not with HOCl. Tissue sections were stained with hematoxylin and eosin (Olympus DP70 Controller, $\times 10$ ). $\mathrm{CB} 2^{-1}$ mice displayed earlier and more extensive lung damages compared with $\mathrm{CB} 2^{+/+}$mice after $\mathrm{HOCl}$ exposure. F: Spontaneous rate of proliferation of fibroblasts isolated from fibrotic skin of $\mathrm{CB}^{+/+}$and $\mathrm{CB} 2^{-/-} \mathrm{C} 57 \mathrm{BL} / 6$ mice submitted to $\mathrm{HOCl}$ or PBS injections. Skin biopsies from the injected areas were collected at the time of sacrifice. Fibroblasts were isolated by collagenase digestion of the skin, then cultured in complete medium. Fibroblast proliferation was determined by pulsing the cells with [3H]thymidine $(1 \mu \mathrm{Ci}$ per well) during the last 16 hours of culture. Results are expressed as absolute counts per minute (cpm). In $\mathbf{A}, \mathbf{C}, \mathbf{D}$, and $\mathbf{F}$, values are means \pm SEM of data. Mean values were compared using unpaired Mann-Whitney $U$ tests. ${ }^{*} P<0.05 ;$ NS indicates nonsignificant.

\section{$\mathrm{CB2}^{-1-}$ Mice Exposed to HOCl Display a Strong and Selective Autoimmune Response Directed Toward DNA-Topoisomerase 1}

Finally, we tested the effect of the inhibition of CB2 signaling on the specific autoimmune response that characterizes the cutaneous diffuse form of SSc. As previously observed in BALB/c mice, no significant levels of antiDNA IgG Abs, anticardiolipine IgG Abs, or rheumatoid factors were detected in the sera of $\mathrm{CB} 2^{+/+}$or $\mathrm{CB} 2^{-/-}$ C57BL/6 mice after three weeks' $\mathrm{HOCl}$ exposure, whereas both $\mathrm{CB} 2^{+/+}$and $\mathrm{CB}^{-/-}$mice developed antiDNA topoisomerase $1 \mathrm{lgG}$ AAbs $\left(P=0.032\right.$ for $\mathrm{CB}^{+/+}$ mice and $P=0.016$ for $\mathrm{CB} 2^{-1-}$ mice versus the respective PBS-injected control mice; Figure 6B and data not shown). In addition, the level of anti-DNA topoisomerase $1 \mathrm{lgG}$ Abs was higher in $\mathrm{HOCl}-\mathrm{CB}^{-1-}$ mice than in $\mathrm{HOCl}-\mathrm{CB} 2^{+/+}$mice $(P=0.032$; Figure $6 \mathrm{~B})$.

\section{Discussion}

In this article, we have shown that the cannabinoid pathway is involved in the control of skin and lung fibrosis and of autoimmunity in SSc. Consequently, we suggest that cannabinoid agonists could represent a new treatment in this life-threatening disease.

In addition to their well-characterized psychoactive effects, cannabinoids display a broad range of properties, through the binding to their receptors CB1 and CB2. These receptors control several central and peripheral functions including neuronal transmission, cardiovascular functions, inflammation, and autoimmunity. They can also modulate cell motility, proliferation, and apoptosis. ${ }^{4}$ In our hands, both nonselective CB1/CB2 and selective CB2 agonists prevent systemic fibrosis in a recently described murine model of SSc mimicking the human disease. The disease, induced by chronic subcutaneous 
A

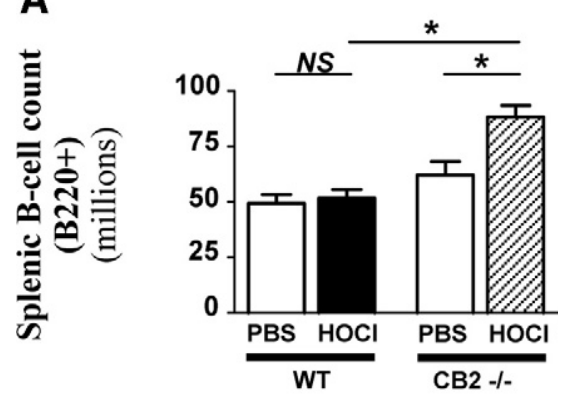

B

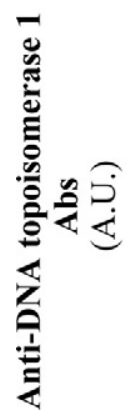

Figure 6. $\mathrm{CB} 2$ silencing increased splenic $\mathrm{B} 220^{+} \mathrm{B}$ cell count and antiDNA-topoisomerase AAb production in $\mathrm{HOCl}-\mathrm{C} 57 \mathrm{BL} / 6$ mice. $\mathrm{CB} 2^{+/+}$and $\mathrm{CB} 2^{-1-} \mathrm{C} 57 \mathrm{BL} / 6$ mice were injected daily for 3 weeks with either an $\mathrm{HOCl}$-generating agent or PBS ( $n=7$ per group). Spleen and sera from those mice were collected at the time of sacrifice. A: Absolute numbers of splenic B220-positive B cells as assessed by flow cytometry. B: Levels of serum anti-DNA-topoisomerase 1 AAbs as detected by ELISA. Values are means \pm SEM of data gained from all mice. Mean values were compared using unpaired Mann-Whitney $U$ tests. ${ }^{*} P<0.05$; NS indicates nonsignificant.

injections of agents generating hypochlorous acid $(\mathrm{HOCl}),{ }^{25}$ includes cutaneous and lung fibrosis, kidney involvement, and the production of serum anti-DNA topoisomerase $1 \mathrm{Abs}$-all features that characterize diffuse cutaneous SSc in humans. Moreover, in these mice, the lung fibrosis is associated with a T cell infiltrate, similar to that observed in human SSc. Experiments performed in SCID mice suggest that $B$ and $T$ lymphocytes are not required for the development of the disease in this new model of SSc. However, the extent of the $\mathrm{HOCl}$-induced pulmonary fibrosis was lower in SCID mice than in immunocompetent mice, indicating that the immune system synergizes with the direct effects of oxidative molecules for the full development of the systemic disease. ${ }^{25}$ In this model, cannabinoid agonists can counteract the profibrogenic effect of $\mathrm{HOCl}$ on skin and lung. Conversely, mice lacking the CB2 receptor are more susceptible to $\mathrm{HOCl}$ and develop enhanced and accelerated skin and lung fibrosis. If CB2 receptor agonists have been found to inhibit LPS-induced pulmonary inflammation, ${ }^{32}$ this is the first report showing the role of the cannabinoid pathway in lung fibrosis. On the other hand, several studies have previously shown the antifibrogenic role of cannabinoid agonists in dermal, cardiac, and liver fibrosis. In a recent work by Akhmetshina et $\mathrm{al}^{24}$ treating mice by the CB2 agonist JWH-133 prevented the profibrotic effect of bleomycin in the skin. In the same model, inhibiting of CB2 signaling increased bleomycin-induced dermal fibrosis. CB2 stimulation by JWH-133 has been shown to protect

murine hearts against fibrosis after myocardial infarction, whereas hearts from $\mathrm{CB}^{-1-}$ mice displayed fibrosis, myocyte hypertrophy, and cardiac dysfunction four weeks after ischemia/reperfusion injury. ${ }^{13}$ In addition, evidence has been reported for the involvement of the cannabinoid pathway in liver fibrosis. Thus, the expression of $\mathrm{CB} 1$ and $\mathrm{CB} 2$ receptors is up-regulated in cirrhotic liver, ${ }^{11}$ but $\mathrm{CB} 1$ and $\mathrm{CB} 2$ stimulations exert opposite effects. Indeed, whereas CB1 is profibrogenic, CB2 activation abrogates the fibrotic process by arresting growth and triggering the apoptosis of myofibroblasts in human cirrhotic liver in vitro. ${ }^{12}$ In line with this result, mice lacking CB2 receptors develop enhanced liver fibrosis after chronic carbon tetrachloride treatment. ${ }^{12}$ Furthermore, CB2 activation not only limits the development of fibrosis but can induce the regression of pre-existing fibrosis, as demonstrated in cirrhotic rats. In those animals, JWH-133 decreases the inflammatory infiltrate in the liver, the number of activated stellate cells and the extension of the fibrosis and increases the expression of the matrix metalloproteinase MMP-2. ${ }^{22}$ We also observed a tendency of pre-existing skin fibrosis to decrease in our mouse model of systemic fibrosis with the cannabinoid agonist WIN-55212 (see supplemental Figure S2 at http://ajp.amjpathol.org). Those results showing a protective role of cannabinoid agonists, especially CB2 agonists, are concordant with those previous results obtained in other fibrotic diseases.

Beside skin and visceral fibrosis, SSc is characterized by $B$ and $T$ cell activation and by the production of AAbs, whose targets differ in the cutaneous limited and in the cutaneous diffuse subtype of SSc. As observed in the cutaneous diffuse form of the human disease, BALB/C and $\mathrm{C} 57 \mathrm{BL} / 6$ mice exposed to $\mathrm{HOCl}$ develop AAbs that selectively target DNA topoisomerase 1. In our hands, the use of agonists of cannabinoid receptors and of mice with silenced CB2 genes as well, has shown the involvement of the cannabinoid pathway to abrogate B cell proliferation and the production of anti-DNA topoisomerase 1 AAbs. The part played by the cannabinoid pathway in immune cell development and activation has been well established. Cannabinoid receptors are expressed in virtually all human peripheral blood immune cells, especially on B cells. However, both human and mouse immune cells express CB2 at higher levels than CB1. ${ }^{33,34}$ The best studied vegetal cannabinoid, $\Delta 9$-tetrahydrocannabinol, is immunosuppressive both in vivo and in vitro, and a reduction in $\mathrm{B}$ cell proliferation and in antibody production has been observed on treatment with cannabinoid agonists. ${ }^{20,35}$ Our results in a mouse model of SSc are in agreement with those observations and with the beneficial effects of cannabinoid agonists in other mouse models of inflammatory autoimmune diseases, such as collagen-induced arthritis $^{36}$ and experimental autoimmune encephalitis. ${ }^{37}$

Altogether, the effects of cannabinoid agonists on fibrogenesis, on the immune system, and on endothelial activation can associate to abrogate the development of SSc. However, the mechanisms through which the cannabinoid pathway controls fibrosis are not fully understood and may be different according to the topography 
of the phenomenon and to its etiology. In our hands, cannabinoid agonists significantly decrease in vitro and in vivo the proliferation rates of dermal fibroblasts. These data argue for a direct role of the cannabinoid pathway on fibroblasts to limit the fibrotic process. It is in agreement with the demonstration that, in hepatic myofibroblasts derived from human cirrhotic liver, CB2 agonists induce both growth arrest and apoptosis through COX-2 activation and reactive oxygen species production, respectively. ${ }^{12}$ Importantly, in our experiments, the nonselective CB1 and CB2 agonist WIN-55,212 dramatically reduces the proliferation rate of fibroblasts in vitro, whereas $\mathrm{JWH}-133$, a selective CB2 agonist, exerts a more moderate inhibitory effect on the proliferation of fibroblasts. Nevertheless, JWH-133 limits the development of skin and lung fibrosis as efficiently as WIN-55,212 in mice exposed to $\mathrm{HOCl}$. Thus, the cannabinoid system might affect the outcome of fibrosis not only by reducing fibroblast proliferation but also indirectly by controlling $B$ cell activation. Consistent with this hypothesis, we observed a decrease in $B$ cell proliferation and in the production of anti-DNA topoisomerase 1 AAbs in mice treated with agonists of cannabinoid receptors and in $\mathrm{CB}^{-1-}$ mice. Other reports are consistent with this hypothesis, suggesting that the cannabinoid pathway limits the fibrotic process by controlling the inflammatory response. ${ }^{14,18}$ In mice exposed to bleomycin, CB2 mediates its antifibrogenic properties by inhibiting leukocyte infiltration in the skin. ${ }^{24}$ In this model of fibrosis, the increased susceptibility of $\mathrm{CB}^{-1-}$ mice to experimental fibrosis was fully replicated by transplantation of CB2deficient bone marrow cells into $\mathrm{CB}^{+/+}$mice. ${ }^{24}$ In cardiac remodeling after ischemia/reperfusion injuries, CB2 activation prevents fibroblast activation and limits macrophage infiltration and TGF- $\beta$ production. ${ }^{13}$ In addition, the cannabinoid system has been shown to activate the synthesis of matrix metalloproteinases that control collagen deposition. ${ }^{22,38}$

In conclusion, modulation of the endocannabinoid system is a novel approach for the treatment of various inflammatory diseases. SSc appears as a privileged condition because the cannabinoid pathway modulates fibroblast proliferation, immune cell activation, and the interaction between endothelial cells and immune cells, all targets that determine the tissular damages in SSc. In this report, we demonstrate for the first time the highly protective role of cannabinoid agonists in SSc. Because these agonists are available and well-tolerated under clinical conditions, our data offer a new therapeutic opportunity in this life-threatening disease.

\section{References}

1. LeRoy EC, Medsger TAJ: Criteria for the classification of early systemic sclerosis. J Rheumatol 2001, 28:1573-1576

2. Herrick AL, Matucci Cerinic M: The emerging problem of oxidative stress and the role of antioxidants in systemic sclerosis. Clin Exp Rheumatol 2001, 19:4-8

3. Lunardi C, Bason C, Navone R, Millo E, Damonte G, Corrocher R, Puccetti A: Systemic sclerosis immunoglobulin $\mathrm{G}$ autoantibodies bind the human cytomegalovirus late protein UL94 and induce apoptosis in human endothelial cells. Nat Med 2000, 6:1183-1186

4. De Petrocellis L, Di Marzo V: An introduction to the endocannabinoid system: from the early to the latest concepts. Best Pract Res Clin Endocrinol Metab 2009, 23:1-15

5. Caraceni P, Domenicali M, Giannone F, Bernardi M: The role of the endocannabinoid system in liver diseases. Best Pract Res Clin Endocrinol Metab 2009, 23:65-77

6. Springs AE, Karmaus PW, Crawford RB, Kaplan BL, Kaminski NE Effects of targeted deletion of cannabinoid receptors CB1 and CB2 on immune competence and sensitivity to immune modulation by Delta9-tetrahydrocannabinol. J Leukoc Biol 2008, 84:1574-1584

7. Croxford JL, Yamamura T: Cannabinoids and the immune system: potential for the treatment of inflammatory diseases? J Neuroimmunol 2005, 166:3-18

8. McPartland JM: Expression of the endocannabinoid system in fibroblasts and myofascial tissues. J Bodyw Mov Ther 2008, 12:169-182

9. Waldeck-Weiermair M, Zoratti C, Osibow K, Balenga N, Goessnitzer E, Waldhoer M, Malli R, Graier WF: Integrin clustering enables anandamide-induced $\mathrm{Ca} 2+$ signaling in endothelial cells via GPR55 by protection against CB1-receptor-triggered repression. J Cell Sci 2008, 121:1704-1717

10. Lépicier P, Lagneux C, Sirois MG, Lamontagne D: Endothelial CB1receptors limit infarct size through NO formation in rat isolated hearts. Life Sci 2007, 81:1373-1380

11. Teixeira-Clerc F, Julien B, Grenard P, Tran Van Nhieu J, Deveaux V, Li L, Serriere-Lanneau V, Ledent C, Mallat A, Lotersztajn S: CB1 cannabinoid receptor antagonism: a new strategy for the treatment of liver fibrosis. Nat Med 2006, 12:671-676

12. Julien B, Grenard P, Teixeira-Clerc F, Tran Van Nhieu J, Li L, Karsak M, Zimmer A, Mallat A, Lotersztajn S: Antifibrogenic role of the cannabinoid receptor CB2 in the Liver. Gastroenterology 2005, 128:742-755

13. Defer N, Wan J, Souktani R, Escoubet B, Perier M, Caramelle P, Manin S, Deveaux V, Bourin MC, Zimmer A, Lotersztajn S, Pecker F, Pavoine C: The cannabinoid receptor type 2 promotes cardiac myocyte and fibroblast survival and protects against ischemia/reperfusion-induced cardiomyopathy. FASEB J 2009, 23:2120-2130

14. Batkai S, Osei-Hyiaman D, Pan H, El-Assal O, Rajesh M, Mukhopadhyay P, Hong F, Harvey-White J, Jafri A, Hasko G, Huffman JW, Gao B, Kunos G, Pacher P: Cannabinoid-2 receptor mediates protection against hepatic ischemia-reperfusion injury. FASEB J 2007, 21:1781-2000

15. Montecucco F, Lenglet S, Braunersreuther V, Burger F, Pelli G, Bertolotto $M$, Mach F. Steffens S: CB2 cannabinoid receptor activation is cardioprotective in a mouse model of ischemia/reperfusion. J Mol Cell Cardiol 2009, 46:612-620

16. Pacher P, Hasko G: Endocannabinoids and cannabinoid receptors in ischaemia-reperfusion injury and preconditioning. $\mathrm{Br} \mathrm{J}$ Pharmacol 2008, 153:252-262

17. Zhang M, Adler MW, Abood ME, Ganea D, Jallo J, Tuma RF: CB2 receptor activation attenuates microcirculatory dysfunction during cerebral ischemic/reperfusion injury. Microvasc Res 2009, 78:86-94

18. Rajesh M, Mukhopadhyay P, Batkai S, Hasko G, Liaudet L, Huffman JW, Csiszar A, Ungvari Z, Mackie K, Chatterjee S, Pacher P: CB2receptor stimulation attenuates TNF-alpha-induced human endothelial cell activation, transendothelial migration of monocytes, and monocyte-endothelial adhesion. Am J Physiol Heart Circ Physiol 2007, 293:2210-2218

19. Klein TW, Newton CA, Widen R, Friedman H: The effect of delta-9tetrahydrocannabinol and 11-hydroxy-delta-9-tetrahydrocannabinol on T-lymphocyte and B-lymphocyte mitogen responses. J Immunopharmacol 1985, 7:451-466

20. Klein TW, Newton C, Friedman H: Cannabinoid receptors and immunity. Immunol Today 1998, 19:373-381

21. Klein TW, Lane B, Newton CA, Friedman H: The cannabinoid system and cytokine network. Proc Soc Exp Biol Med 2000, 225:1-8

22. Munoz-Luque J, Ros J, Fernandez-Varo G, Tugues S, Morales-Ruiz M, Alvarez CE, Friedman SL, Arroyo V, Jimenez W: Regression of fibrosis after chronic stimulation of cannabinoid CB2 receptor in cirrhotic rats. J Pharmacol Exp Ther 2008, 324:475-483

23. Karsak M, Gaffal E, Date R, Wang-Eckhardt L, Rehnelt J, Petrosino S Starowicz K, Steuder R, Schlicker E, Cravatt B, Mechoulam R, Buettner R, Werner S, Di Marzo V, Tüting T, Zimmer A: Attenuation of allaergic 
contact dermatitis through the endocannabinoid system. Science 2007, 316:1494-1497

24. Akhmetshina A, Dees C, Busch N, Beer J, Sarter K, Zwerina J, Zimmer A, Distler O, Schett G, Distler JHW: The cannabinoid receptor CB2 exerts antifibrotic effects in experimental dermal fibrosis. Arthritis Rheum 2009, 60:1129-1136

25. Servettaz A, Goulvestre C, Kavian N, Nicco C, Guilpain P, Chéreau C, Vuiblet V, Guillevin L, Mouthon L, Weill B, Batteux F: Selective oxidation of DNA topoisomerase 1 induced systemic sclerosis in the mouse. J Immunol 2009, 182:5855-5864

26. Buckley NE, McCoy KL, Mezey E, Bonner T, Zimmer A, Felder CC, Glass M, Zimmer A: Immunomodulation by cannabinoids is absent in mice deficient for the cannabinoid $\mathrm{CB}(2)$ receptor. Eur J Pharmacol 2000, 396:141-149

27. Servettaz A, Tamby MC, Guilpain P, Reinbolt J, Garcia De La PenaLefebvre P, Allanore Y, Kahan A, Meyer O, Guillevin L, Mouthon L: Anti-endothelial cell antibodies from patients with limited cutaneous systemic sclerosis bind to centromeric protein B (CENP-B). Clin Immunol 2006, 120:212-219

28. Tamby MC, Humbert M, Guilpain P, Servettaz A, Dupin N, Christner JJ, Simonneau G, Fermanian J, Weill B, Guillevin L, Mouthon L: Antibodies to fibroblasts in idiopathic and scleroderma-associated pulmonary hypertension. Eur Respir J 2006, 28:799-807

29. Dalle-Donne I, Rossi R, Giustarini D, Gagliano N, Lusini L, Milzani A, Di Simplicio P, Colombo R: Actin carbonylation: from a simple marker of protein oxidation to relevant signs of severe functional impairment. Free Radic Biol Med 2001, 1:1075-1083

30. Burdick MD, Murray LA, Keane MP, Xue YY, Zisman DA, Belperio JA, Strieter RM: CXCL11 attenuates bleomycin-induced pulmonary fibro- sis via inhibition of vascular remodeling. Am J Respir Crit Care Med 2005, 171:261-268

31. Preud'homme JL, Rochard E, Gouet D, Danon F, Alcalay M, Touchard $G$, Aucouturier P: Isotypic distribution of anti-double-stranded DNA antibodies: a diagnostic evaluation by enzyme-linked immunosorbent assay. Diagn Clin Immunol 1988, 5:256-261

32. Berdyshev E, Boichot E, Corbel M, Germain N, Lagente V: Effects of cannabinoid receptor ligands on LPS-induced pulmonary inflammation in mice. Life Sci 1998, 63:125-129

33. Schatz AR, Lee M, Condie RB, Pulaski JT, Kaminski NE: Cannabinoid receptors CB1 and CB2: a characterization of expression and adenylate cyclase modulation within the immune system. Toxicol Appl Pharmacol 1997, 142:278-287

34. Galiegue S, Mary S, Marchand J, Dussossoy D, Carriere D, Carayon P. Bouaboula M, Shire D, Le Fur G, Casellas P: Expression of central and peripheral cannabinoid receptors in human immune tissues and leukocyte subpopulations. Eur J Biochem 1995, 232:54-61

35. Klein TW, Newton C, Zhu W, Daaka Y, Friedman H: Delta 9-Tetrahydrocannabinol, cytokines, and immunity to Legionella pneumophila. Proc Soc Exp Biol Med 1995, 209:205-212

36. Malfait AM, Gallily R, Sumariwalla PF, Malik AS, Andreakos E, Mechoulam R, Feldmann M: The nonpsychoactive cannabis constituent cannabidiol is an oral anti-arthritic therapeutic in murine collagen-induced arthritis. Proc Natl Acad Sci U S A 2000, 97:9561-9566

37. Arevalo-Martin A, Vela JM, Molina-Holgado E, Borrell J, Guaza C: Therapeutic action of cannabinoids in a murine model of multiple sclerosis. J Neurosci 2003, 23:2511-2516

38. Ramer R, Hinz B: Inhibition of cancer cell invasion by cannabinoids via increased expression of tissue inhibitor of matrix metalloproteinases-1. J Natl Cancer Inst 2008, 100:59-69 